\title{
The "Immersive" as a Model for Action in Artworks from the Brazilian Avant-Garde
}

\author{
DEBORA FACCION \\ Artist, PhD Candidate at SUNY Binghamton
}

\begin{abstract}
The concept of "immersive" gives us a practical direction to embodying the understanding of art works created by avant-garde Brazilian artists. Building upon Simone Osthoff's seminal argument about the legacy of "interactivity" in works by Helio Oiticica and Lygia Clark, in this paper I suggest that the "immersive" presents a better model for encompassing the experience of works by artists like Antonio Dias and Anna Maria Maiolino, in their historical and material potencies. By looking at works of painting and photography by these artists, instead of installations or objects, we need to consider "immersion" beyond its technological capacity, activating, then, its parallel with Oswald de Andrade's modernist concept of Anthropophagy, which was actualized by these artists in the 1960s and 70s, and continues to resonate with many of our current search for the decolonial.
\end{abstract}
A woman cutting off her own tongue.
Cutting off her own nose.
Or finding the courage to do so.
Starting the action of cutting, positioning the scissors on her skin, and taking a picture.
Creating an image of the feeling of being without voice or breath, of cutting off, censoring one's senses.

These descriptions of Anna Maria Maiolino's series Photopoemactions (Figure 1) actualize the experience created by viewing these images. Maiolino's title for these images-

Photopoemactions - shows the artist's intention to create an experience extending beyond visual perception; seeing this image (the photo) creates subjective involvement (the poem) that positions the viewer at the beginning of an action. Moreover, the three words combined into one in the title suggest that these photographs do not function simply as representational images but rather as a thing that wields action. Indeed, "action," the final term in Maiolino's title, was central in the avant-garde art projects carried out by Brazilian artists in the late 1960s. In January 1967, seventeen Brazilian artists and art critics signed the "Declaration of the Basic Principles of AvantGarde," stating that the ideal of "avant-garde art" (or in Portuguese, arte de vanguarda) was to create art that "contributes to changing situations of passivity or stagnation" by "being manifested in every area of human sensibility and consciousness." 1 The document ended with a call for using "every medium ... from the newspapers to forums ... from the pamphlets to cinema, from the 
transistor to the television." 2 The use of various media in their artistic practice showed the expansive notion of art held by these artists, which was accompanied by an equally broad perspective on avant-gardism, centered on the artist's "freedom of being." 3 The Declaration played a vital role for these Brazilian artists as a tool to position themselves as a group that would support each other's practices during the military dictatorship that had ruled the country beginning in 1964. More importantly, it expressed the effort to create a cohesive project that was capable of sustaining a multiplicity of art practices while resisting institutionalization and the consumer market.

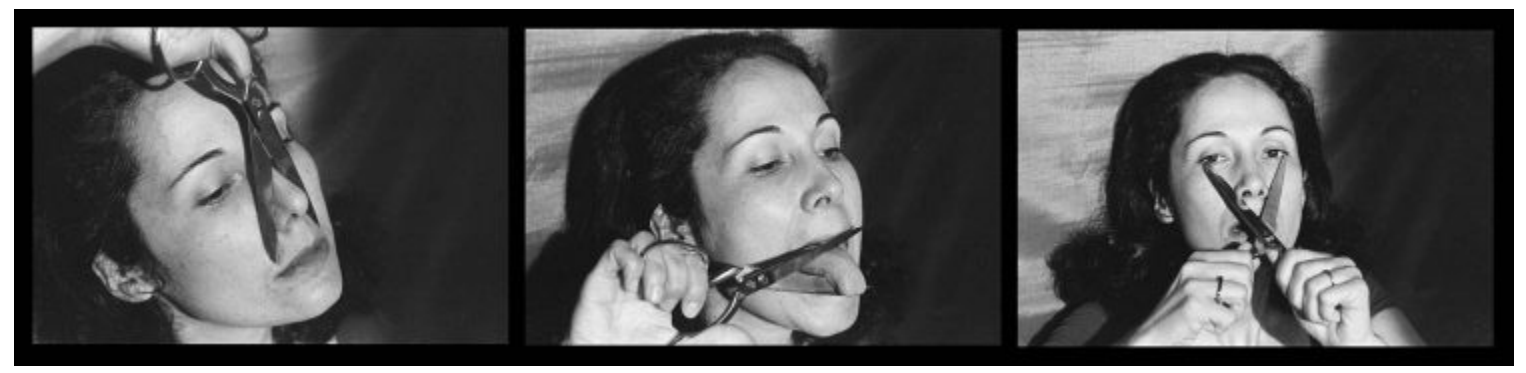

Figure 1. Anna Maria Maiolino, O que sobra (What is left), from the series Photopoemaction, 1974 , black and white photographs and digital print, $62 \times 153 \mathrm{~cm}$. Image courtesy of the artist.

Although the Declaration is not the founding document of Brazilian avant-garde, its significance relies on the clarity with which those who signed it expressed the ideal behind creating and supporting art that would intentionally impact society. This ideal was found in the Declaration within the same lines that promoted the use of diverse media-including electronic media_for making art, arguing that the use of non-traditional media enabled interaction with a broad public. Simone Osthoff analyzed the work of Helio Oiticica and Lygia Clark, two artists who also signed the Declaration, in their capacity for creating interaction, arguing that these artists "contributed to the development of an original vocabulary of interactivity."4 Osthoff's 1997 article was seminal in establishing a relation between these artists' works and the early technological experiments taking place at the time that aimed at expanding human consciousness and perception through electronic sensorial stimulation. Osthoff pointed out that "although not technologically based, Clark and Oiticica's works are ... related conceptually to those of artists pushing interactivity into new territories. . . Clark, merging the body/mind duality, focused primarily on the subjective and psychological dimensions of sensorial experimentation, while Oiticica engaged in sensorial explorations involving social, cultural, architectural and environmental spaces.",

To sustain her argument, Osthoff created parallels, for example, between Lygia Clark's “Mask with Mirrors" (1976) and Ivan Sutherland's work with virtual reality (1968), signaling the exploration of the visual sense as the converging point between the two: "Clark's mask holds small moveable mirrors in front of the eyes," while Sutherland's work was "based on the introduction of stereoscopic head-mounted displays." Aside from similarities in the configuration of the binocular structures and other comparisons that Osthoff makes between Clark and Oiticica's works and early technological developments, Osthoff's article focuses on Clark's and Oiticica's artistic trajectories, emphasizing that their quest for interactivity allied with "material precariousness" and that their work developed "from purely optical-formal concerns to 
participatory and body-based work."7 The originality of Osthoff's argument persists after twenty years, despite growing interest, with numerous exhibitions and research conducted around the work of these artists because of her insistence that interactivity isn't "related exclusively to technological approaches" but is "tied viscerally to the continuing development of a new

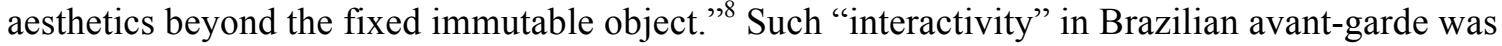
determined by the cultural paradigm created by the concept of anthropophagy, as proposed by Oswald de Andrade in $1928 .^{9}$

As Suely Rolnik explains, the anthropophagous movement is the reaffirmation of what she calls an "ethical formula" that governs a relation of alterity, inspired in the native Tupi ritual in which one chooses an other based on the vitality that the other provides, and then allows oneself to be "affected by those desired others to the point of absorbing them into their own bodies." 10 Through Rolnik's lens, we can see that the inter-relational tendencies in Brazilian avant-garde of the late 1960s are not merely a technological embrace of "interactivity". Rather, they are the result of a particular mode of relation, one that requires the "integration of the particles of the virtue" of the other "into the chemistry of the anthropophagous" soul."11 Therefore, the artists" intention to impact society, as stated in the Declaration, had a specific cultural condition that employed visual art as a means to affect the entire body, understood here both in its individual and cultural dimensions. According to Michael Asbury:

The renewed interest in Oswald de Andrade during the 1960s pertained to the politicized context of debates around North American cultural imperialism and the assertion of a national identity that resisted alliance with the crude nationalism promoted by the dictatorship. The viscerality implied by the term appropriately expressed the conditions of life under the constant threat of violence. The issue of alterity evoked by the Oswaldian irreverence was powerfully ambivalent, enough to contain a critical positioning in the light of geopolitical hierarchies, a mockery of a regime that proclaimed what it desired as the essential national character, and the possibility of absorbing a set of cultural references to express subjective experience. ${ }^{12}$

If we return to the descriptions of Maiolino's images with which we began, we can understand how these images establish a relation that prompts the viewer to "express subjective experience", with a strong affective response (particularly to the vulnerability of the tongue, held between the blades of a pair of scisors). Photopoemactions simultaneously creates a chilling feeling - one that impacts us personally and physically, because it deals directly with the sensation of our own bodies - as well as a symbolic understanding, given the ritualistic nature of the action depicted. Further, these images appeal to the realm of culture because these images contain almost a prescriptive quality, a how-to that suggests that cutting off one's senses is part of a systematic action - which, in this case, we can place in the context of the censorship imposed by the military state in Brazil. Anthropophagy meant overcoming the ambivalence of the body as capable of absorbing material experiences and expressing them culturally.

Thus, in the quest for the "development of a new aesthetics beyond the fixed immutable object," as proposed by Osthoff, I suggest that the "immersive" presents a better model through which to understand the work created by Brazilian avant-garde artists in their legacy to the use of technology in art rather than "interactivity." 13 The move from a purely visual art to a "body-based work" capable of creating a "subjective experience" has the phenomenological quality of the "immersive," that is, the quality of the body in action through the actualization of its 
surroundings. To further develop this idea, I want to turn our attention to Anywhere Is My Land, a painting by Antonio Dias, one of the main artists who wrote the "Declaration of the Basic Principles of Avant-Garde," and the concept of the "virtual," which accompanies most of the recent studies of immersive environments.

I borrow the term "virtual" here from Gilles Deleuze, who, in Difference and Repetition, published in 1968, the same year as Anywhere Is My Land was painted, developed the concept. Deleuze adapted the concept of the "virtual" from Henri Bergson to reorient philosophical attention away from reality as a thing-in-the-world and toward reality understood as an event-as the plane of incessantly emerging potential. For Deleuze, "The virtual is the characteristic state of ideas," which is to say the very state of flux, endless potential through an endless process of change. ${ }^{14}$ Deleuze's definition helps us understand a realm of existence beyond the "fixed immutable object"; this existence is manifested once someone actualizes an experience. It is indeed a very abstract concept. Yet, the virtual seems to be the best concept with which to bridge the proposition of a painting like Anywhere Is My Land and the experience that it actualizes, keeping in mind the cultural paradigm of anthropophagy.

In its purely visual capacity, Anywhere Is My Land can be described as white drops of paint randomly distributed on a black surface that is carefully divided into a map-like grid. From such a description, we immediately consider the possibility of it being a map of the starry sky, although we are confronted by the title on the painting, stating that it is a map of a land. As we struggle with the materiality of the painting, we are also prompted by the format of the map to try and situate our bodies within this imaginary space. Here, the grid, which establishes the time/space understanding of a map, functions as the element on the painting that propels us into an immersive condition (the in-between pure potentiality — the virtual — and actual existence): It is the grid that creates the ambivalence on the image of something that at first looks like chaos, but at the same time appears to have been already systematized. As Rosalind Krauss noted in her 1979 canonical essay "Grids," "The grid's mythic power is that it makes us able to think we are dealing with materialism (or sometimes science, or logic) while at the same time it provides us with a release into belief (or illusion, or fiction)." "The anthropophagic perspective resolves such ambivalence between materialism and belief by placing the actualization of the artwork within the experience of the viewer's body.

However, it is important to remember that the actualization in Dias takes place through the tropes of painting available in the artist's postwar moment. Dias's painting plays on paradox: Its perfectly smooth background and precisely flat lines and letters contrast with casual, dimensional drops of paint. The resulting image, uncannily similar to the computer printouts and electronic screens of its day, solicits a mode of observation specific to painting from the viewer. The viewer looks for the gesture of the artist in the brushstroke, for symbols and elements that signify something, and from there aims to construct a story familiar from the history of painting (or at least the modernist dialectic between flatness and illusion). Instead, Dias's painting frustrates all these attempts, and, by doing so, Anywhere Is My Land becomes what Hélio Oiticica dubbed "the open exercise of significative behavior," that is, the understanding that depends on the action of the viewer. ${ }^{16}$ Here, we return to Deleuze's concept of the "virtual." As the philosopher wrote in Difference and Repetition, "For a virtual object, to be actualized is to create divergent lines which correspond to - without resembling - a virtual multiplicity. The virtual possesses the reality of a task to be performed or a problem to be solved: it is the problem which orientates, conditions and 
engenders solutions."17 Therefore, Dias's Anywhere Is My Land initiates an immersive event inasmuch as (considering the historical context accompanied by the anthropophagic perspective) it prompts the viewer to access a realm beyond the "fixed immutable object" of the painting. Put simply, at the same time that Anywhere Is My Land engenders a solution of how to situate oneself within a land, the painting poses the problem of how to situate oneself using this exceptionally inexpressive map. This back-and-forth of problems and solutions keeps the viewer in an active position that appeals to divergent modes of actualization. The painting does not merely ask for interpretation; instead, much like Rolnik defined anthropophagy as "cartographing," the map in Anywhere Is My Land "participates in the construction of the territory it represents, in the taking shape of a new figure of one's self, a new 'at home,' a new world.",18

To better understand the legacy of Brazilian avant-garde artists like Oiticica, Clark, Dias, and Maiolino, the move from "interactivity" to "immersion" is fundamental in sustaining the decolonial project present in the anthropophagic perspective adopted in the 1960s. While "interactivity," as argued by Osthoff, was sufficient to describe the relation between the public and artworks, which as she points out already presents institutional challenges in conserving, exhibiting and collecting such artworks, the notion of immersion more effectively tackles the dismantling of the logic that separates the body from the cultural experience.

\section{ACKNOWLEDGEMENTS}

This paper is an experiment in thinking and making that I was lucky to find a panel organized by women artists and theorists who could embrace it, therefore, I'm very thankful to Gabriela Aceves-Sepulveda and Matilda Aslizadeh for inviting me to the New Media Caucus panel at CAA, 2017 in Los Angeles to present this work. I also need to acknowledge Professor Kevin Hatch who accompanied the growing of the thought economically presented in this article, and Kevin Hamilton for his open-minded and patient work as editor of the New Media Caucus.

\section{REFERENCES}

${ }^{1}$ Dias, Antonio et al. "Declaração de princípios básicos da vanguarda." In: Fundação Armando Alvares Penteado. Departamento de Pesquisa e Documentação de Arte Brasileira. 1978. Objeto Na Arte : Brasil Anos '60. [São Paulo]: [Departamento de Pesquisa e Documentação de Arte Brasileira, Fundação Armando Alvares Penteado].

${ }^{2}$ Ibid.

${ }^{3}$ Ibid.

${ }^{4}$ Osthoff, Simone. 1997. "Lygia Clark and Helio Oiticica: A Legacy of Interactivity and Participation for a Telematic Future." Leonardo -Oxford then Cambridge Ma- 30 (4): 279-290.

${ }^{5}$ Osthoff, p.280.

${ }^{6}$ Osthoff, p. 279 .

${ }^{7}$ Osthoff, p.286.

${ }^{8}$ Osthoff, p.288.

9 Andrade, Oswald de. 1928, "Manifesto Antopófago". In: Andrade, Oswald de. 2011. A Utopia antropofágica. São Paulo: Editora Globo. 
${ }^{10}$ Rolnik, Suely., “Antropophagic Subjectivity”. In Lafuente, Pablo,,Lagnado, Lisette,,. 2015. Cultural Anthropophagy: The 24th Bienal De São Paulo 1998. *Translated from the Portuguese by Michael Reade, Erika Benincasa, Alfred MacAdam and Nadine, p.3, 1998. (Available at: http://www.caosmose.net/suelyrolnik/pdf/anthropophagic subjectivity.pdf) ${ }^{11}$ Ibid.

${ }^{12}$ Asbury, Michel. 2009. "Anna Maria Maiolino: Order and Subjectivity". In Maiolino, Anna Maria. Pharos Centre for Contemporary Art. $<$ Leukōsia>. 2009. Anna Maria Maiolino, Order and Subjectivity. Nicosia: Pharos Publ, p.27.

${ }^{13}$ Here, I am adopting an understanding of the immersive that is close to what Merleau-Ponty developed as a phenomenological understanding of the world. In Eye and Mind (1964) he wrote, "no longer (...) a network of relations between objects such as would be seen by a witness to my vision or by a geometer looking over it and reconstructing it from the outside. It is, rather, a space reckoned starting from me as the zero point or degree zero of its spatiality. I do not see it according to its exterior envelope; I live it from the inside; I am immersed in it. After all, the world is all around me, not in front of me." In Merleau-Ponty, Maurice, Edie,James M. 2015. The Primacy of Perception: And Other Essays on Phenomenological Psychology, the Philosophy of Art, History and Politics, p. 178.

${ }^{14}$ Deleuze, Gilles (trans. Paul Patton). 1968. Difference and Repetition, London: The Athlone Press, 1994, p.211.

${ }^{15}$ Krauss, Rosalind E.,. 2010. The Originality of the Avant-Garde and Other Modernist Myths. Cambridge, Mass. u.a.: MIT Press.

${ }^{16}$ Project-Book, by Antonio Dias, with introductory text by Helio Oiticica (London, 1969), unpublished - available as image in: Dias, Antonio, Achille Bonito Oliva, and Paulo Sérgio Duarte. 2015. Antonio Dias. São Paulo, SP, Brazil : Associação para o Patronato Contemporâneo, APC : COSACNAIFY, 2015.

${ }^{17}$ Deleuze, p. 212.

${ }^{18}$ Rolnik, p.8.

\section{AUTHOR BIO}

Debora Faccion is a visual artist from Brazil and a PhD candidate in Art History, at SUNY

Binghamton. Her work deals with the translation of concepts and values between cultures, as well as the constraints and possibilities of different media used by artists. In her dissertation, she focuses on the work by Brazilian artist Antonio Dias, within the social and political context of the 1970s. She was a graduate intern at the Getty Research Institute in Los Angeles in 2015-16, where she also worked translating Brazilian Concrete poetry to English. Currently, she is an Adjunct Lecturer in the Art \& Design department at Binghamton University, teaching a course on "Critical Theory and Creativity" in the BFA program. 